\title{
Decoded codes of Comet Halley
}

\author{
Lutvo Kurić \\ Institute of Economics, University of Sarajevo, Trg Oslobođenja 1, Sarajevo, \\ Bosnia and Herzegovina \\ E-mail address: lutvokuric@yahoo.com
}

\begin{abstract}
The subject of the research we are discussing in this text is the cyber-information access to the research of the harmonic dynamics of comet Halley. Cosmic mechanics has been always a perfect example of the regular, deterministic, motion which allows a prediction to a fairly high accuracy. The analysis of these data allowed us to conclude that the motion of Halley's comet is harmonious.
\end{abstract}

Keywords: Halley's comet; orbit diagram; orbital code

\section{INTRODUCTION}

Comet Halley can be represented by two different forms, ie, a discrete form and a sequential form. In the discrete form, a Comet Halley is represented by a set of discrete codes or a multiple dimension vector. In the sequential form, a Comet Halley is represent by a their orbital and physical characteristics.

What we did is the following: We translated the orbital and physical parameters from the language of comet Halley into the digital language of programmatic, cybernetic and information principles. This we did by using the adequate mathematical algorithms. By using orbital and physical characteristics, we calculated the numerical value for the information content of orbital and physical characteristics of this comet. What we got this way is the digital picture of comet Halley. These digital pictures reveal to us a whole new dimension of this comet. They reveal to us that the orbital and physical language of this comet is strictly conditioned and determined by programmatic, cybernetic and information principles [1-25].

\section{ALGORITHM}

Period: From 25 January 66 AD to 9 February 1986.

$66,141,218,295,374,451,530,607,684,760,837,912,989,1066$, $1145,1222,1301,1378,1456,1531,1607,1682,1759,1835,1910$ and 1986. 
Box-and-whisker chart:

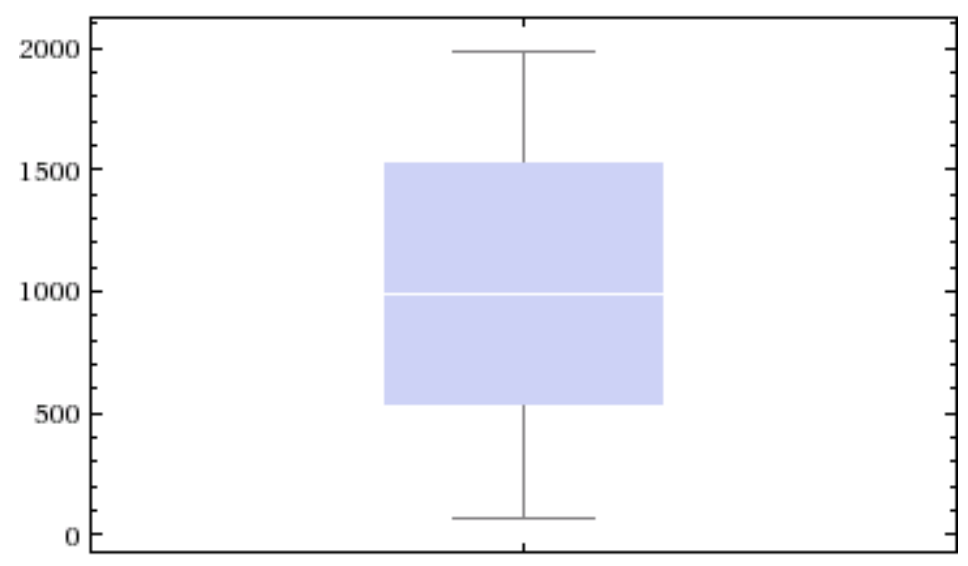

Differences:
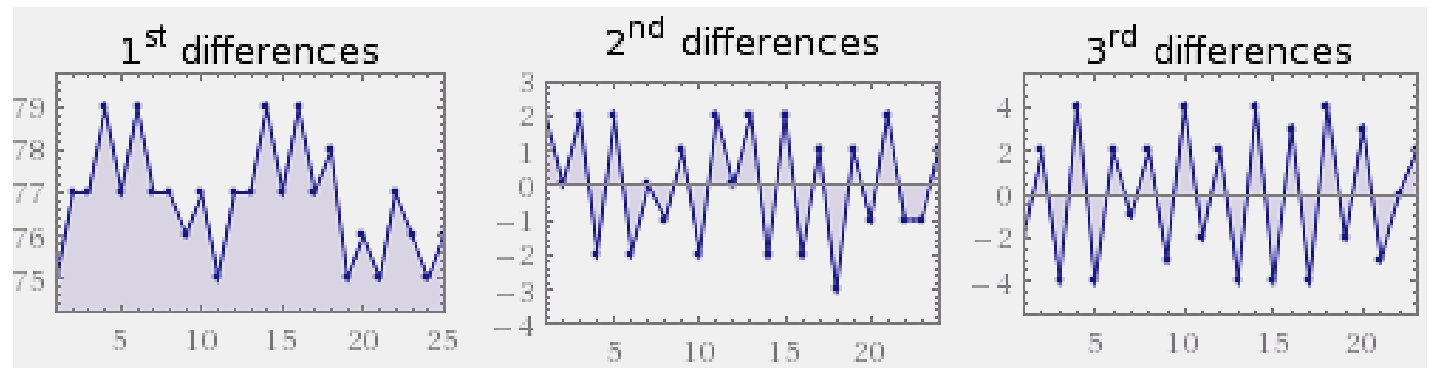

kurtosis

$\{66,141,218,295,374,451,530,607,684$,

$760,837,912,989,1066,1145,1222,1301,1378$,

$1456,1531,1607,1682,1759,1835,1910,1986\}$

\section{RESULT}

$$
\frac{1136776385637599}{634202975483045} \approx 1.79245
$$

Histogram:

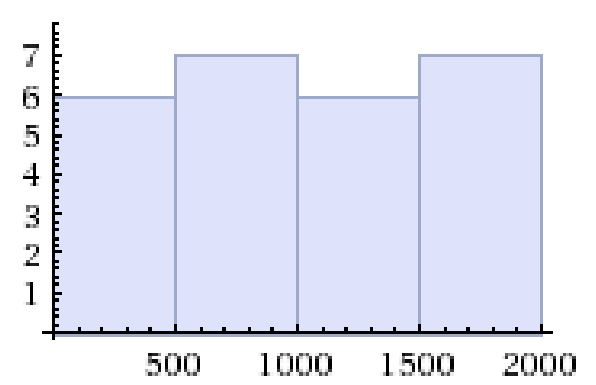




\section{plot |Fourier[}

$\{66,141,218,295,374,451,530,607,684,760,837,912,989,1066,1145$, $1222,1301,1378,1456,1531,1607,1682,1759,1835,1910,1986\}] \mid$

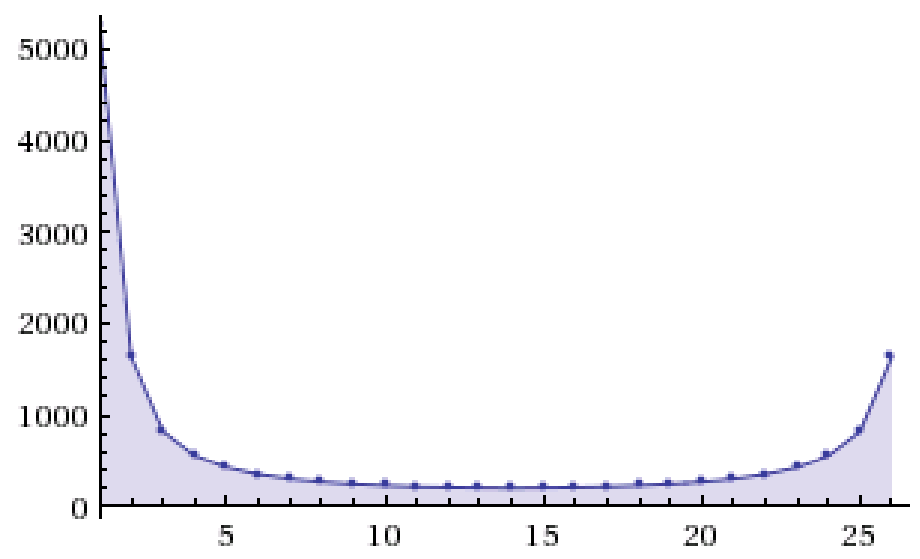

Progression 1 (Dates from 66 to 1986)

$$
\begin{gathered}
\mathrm{D}_{1}=66 ; \mathrm{D}_{2}=141 ; \mathrm{D} 3=218 ; \ldots \mathrm{D}_{26}=1986 \\
{\left[\mathrm{D}_{1}+\left(\mathrm{D}_{1}+\mathrm{D}_{2}\right)+\left(\mathrm{D}_{1}+\mathrm{D}_{2}+\mathrm{D}_{3}\right) \ldots,+\left(\mathrm{D}_{1}+\mathrm{D}_{2}+\mathrm{D}_{3} \ldots,+\mathrm{D}_{26}\right)\right]=\mathrm{APa} 1,2,3, \mathrm{n}} \\
\mathrm{D}_{1}=\mathrm{APa} 1=66 ; \\
\left(\mathrm{D}_{1}+\mathrm{D}_{2}\right)=(66+141)=\mathrm{APa} 2=207 ; \\
\left(\mathrm{D}_{1}+\mathrm{D}_{2}+\mathrm{D}_{3}\right)=(66+141+218)=\mathrm{APa} 3=425 \\
\left(\mathrm{D}_{1}+\mathrm{D}_{2}+\mathrm{D}_{3} \ldots,+\mathrm{D}_{26}\right)=\mathrm{APa} 26=\mathbf{2 6 7 4 2} ; \\
\mathrm{APa} 1,2,3, \mathrm{n}=\mathrm{Progression} \text { of the date } 1,2,3, \mathrm{n} \\
\left.\left.\left[\mathrm{APa} 1+\mathrm{APa}_{2}+\mathrm{APa}_{3}\right) \ldots,+\mathrm{APa} 26\right)\right]=(66+207+425 \ldots,+26742)
\end{gathered}
$$

Progression 2 (Dates from 1986 to 66)

$$
\begin{gathered}
\mathrm{D}_{26}=1986 ; \mathrm{D}_{25}=1910 ; \mathrm{D} 24=1835 ; \ldots \mathrm{D}_{1}=66 ; \\
{\left[\mathrm{D}_{26}+\left(\mathrm{D}_{26}+\mathrm{D}_{25}\right)+\left(\mathrm{D}_{26}+\mathrm{D}_{25}+\mathrm{D}_{24}\right) \ldots,+\left(\mathrm{D}_{26}+\mathrm{D}_{25}+\mathrm{D}_{24 \ldots,}+\mathrm{D}_{1}\right)\right]=\mathrm{APb}_{1,2,3, \mathrm{n}}} \\
\mathrm{D}_{26}=\mathrm{APb} 26=1986 ; \\
\left(\mathrm{D}_{26}+\mathrm{D}_{25}\right)=(1986+1910)=\mathrm{APb} 25=3896 \\
\left(\mathrm{D}_{26}+\mathrm{D}_{25}+\mathrm{D}_{24}\right)=(1986+1910+1835)=\mathrm{APb} 3=5731 ; \\
\left(\mathrm{D}_{26}+\mathrm{D}_{25}+\mathrm{D}_{24 \ldots},+\mathrm{D}_{1}\right)=\mathrm{APb} 1=\mathbf{2 6 7 4 2} ; \\
\mathrm{APb}_{3,2,1, \mathrm{n}}=\mathrm{Progression} \text { of the date } 3,2,1, \mathrm{n} \\
\left.\left.\left[\mathrm{APb}_{26}+\mathrm{APb}_{25}+\mathrm{APb}_{24}\right) \ldots,+\mathrm{APb}_{1}\right)\right]=(1986+1910+1835 \ldots,+66)=\mathbf{2 6 7 4 2}
\end{gathered}
$$


This table contains information on getting of Halley's comet in our solar system in the following years 66 and 1986nd.

- Next perihelion predicted 28 July 2061

- Next perihelion predicted 2137

etc.

Arrival date of Halley's comet (1)

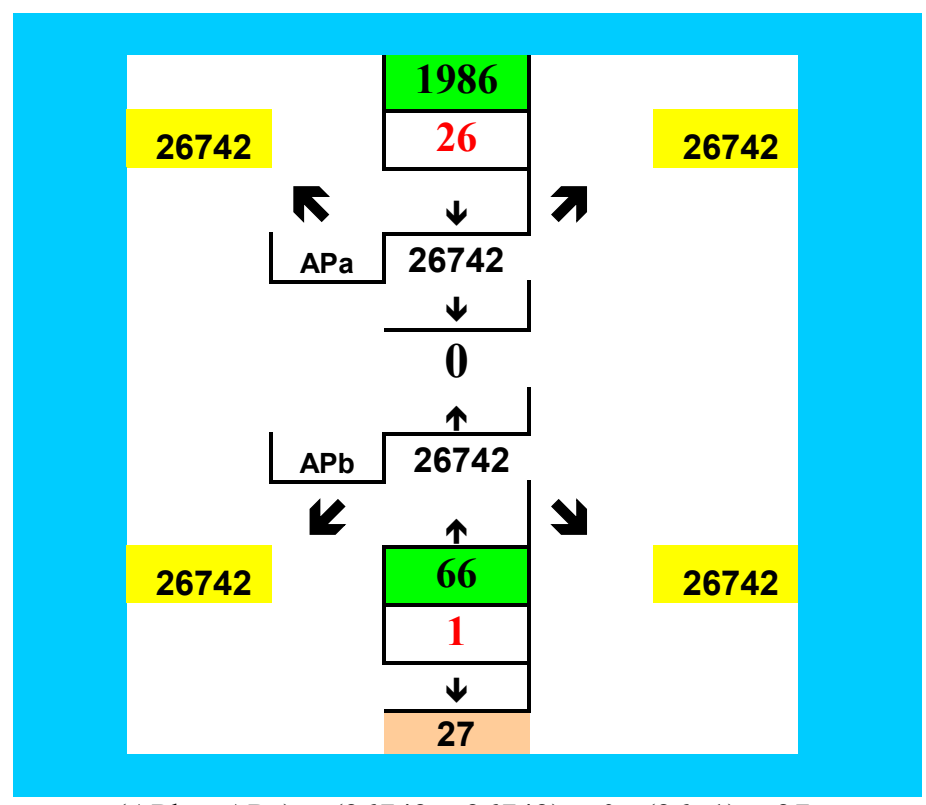

$(\mathrm{APb}-\mathrm{APa})=(26742-26742)=0 ;(26+1)=27 ;$

This table contains information on getting of Halley's comet in our solar system in the following years 66 and 1986nd.

Arrival date of Halley's comet (2)

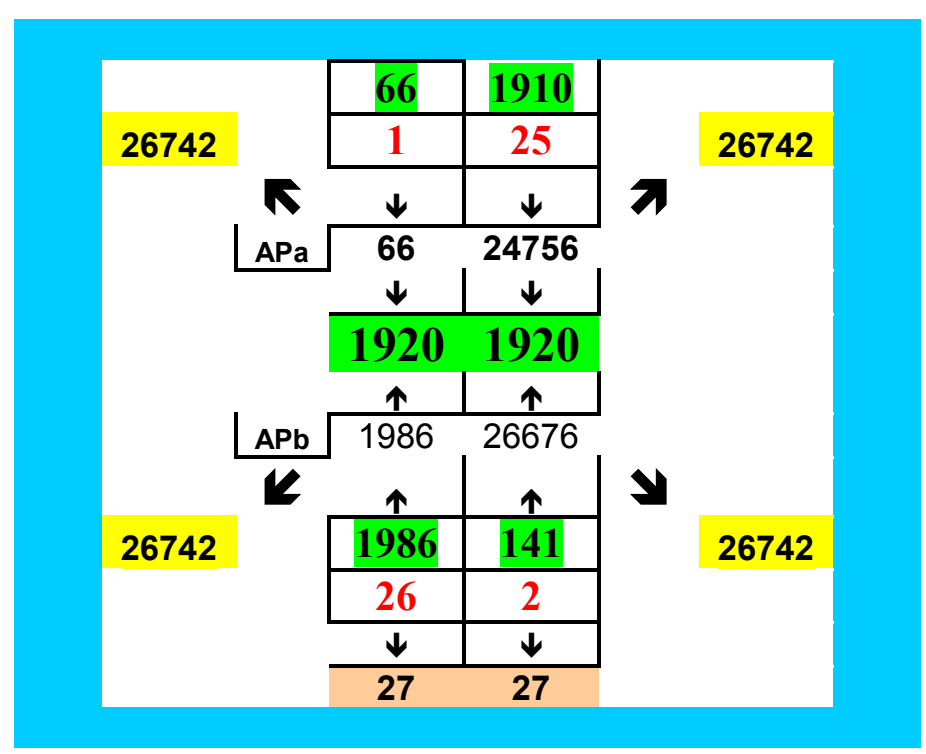




$$
\begin{gathered}
(1986-66)=1920 ;(26676-24756)=1920 ;(1+26)=27 ;(25+2)=27 ; \\
(1986+24756)=26742 ;(26676+66)=26742 ;
\end{gathered}
$$

This table contains information on getting of Halley's comet in our solar system in the following years: 66, 141, 1910 and 1986nd.

Arrival date of Halley's comet (3)

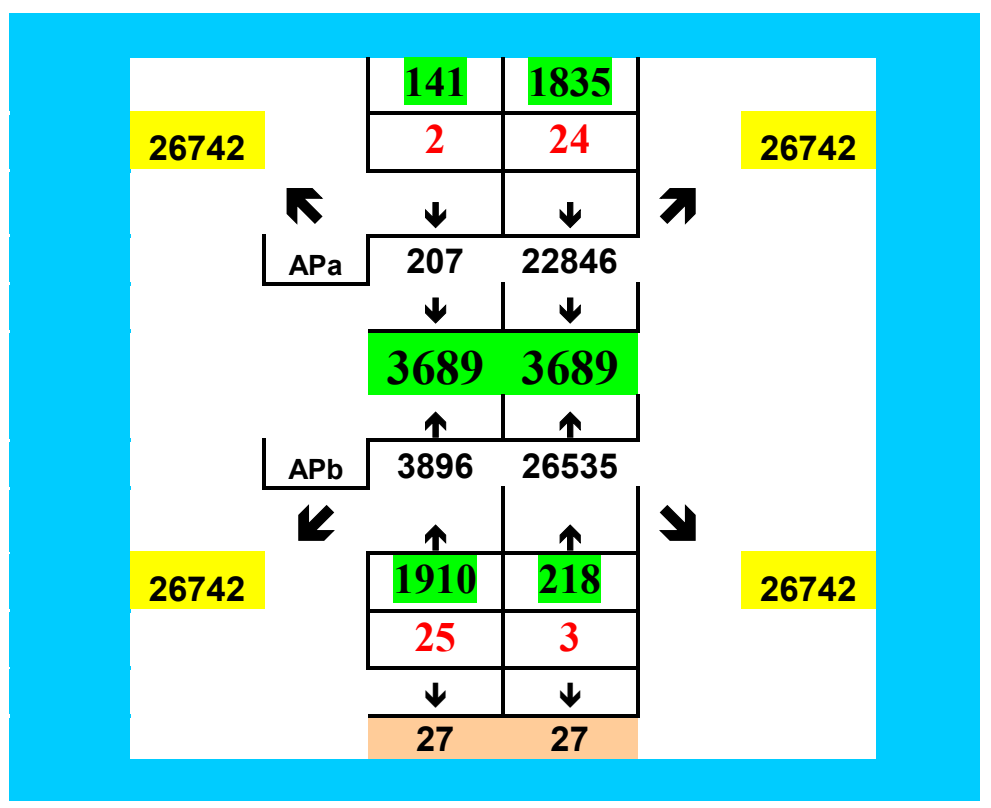

This table contains information on getting of Halley's comet in our solar system in the following years: 141, 218, 1835 and 1910nd.

Arrival date of Halley's comet (4)

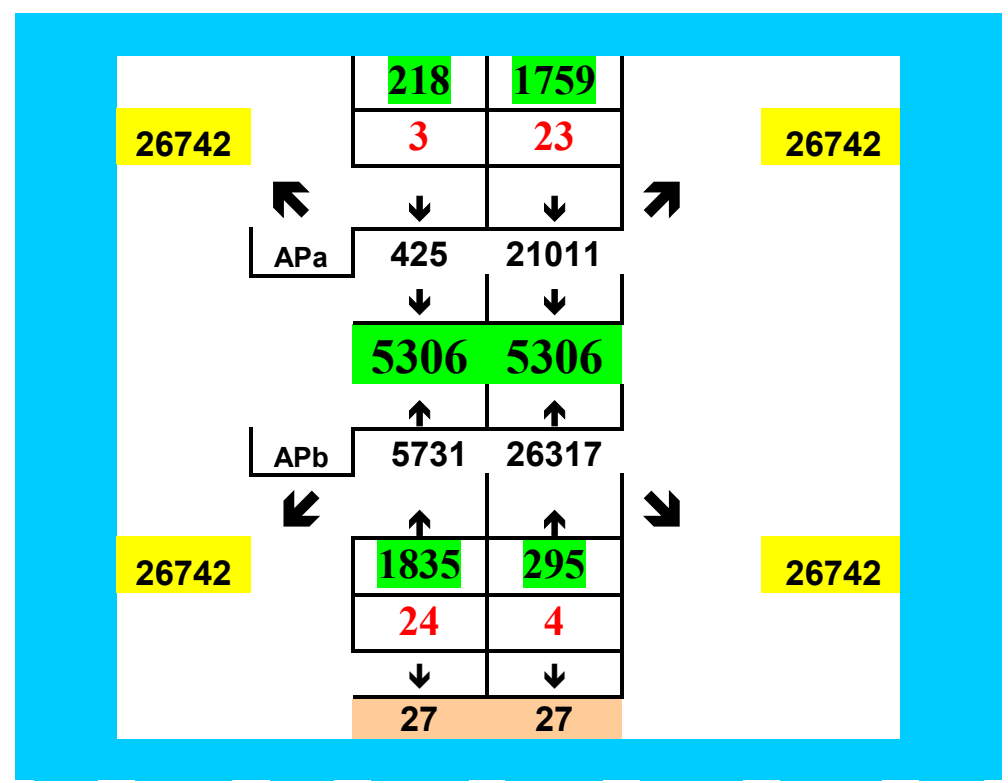


This table contains information on getting of Halley's comet in our solar system in the following years: 218, 295, 1759 and 1835nd.

Arrival date of Halley's comet (5)

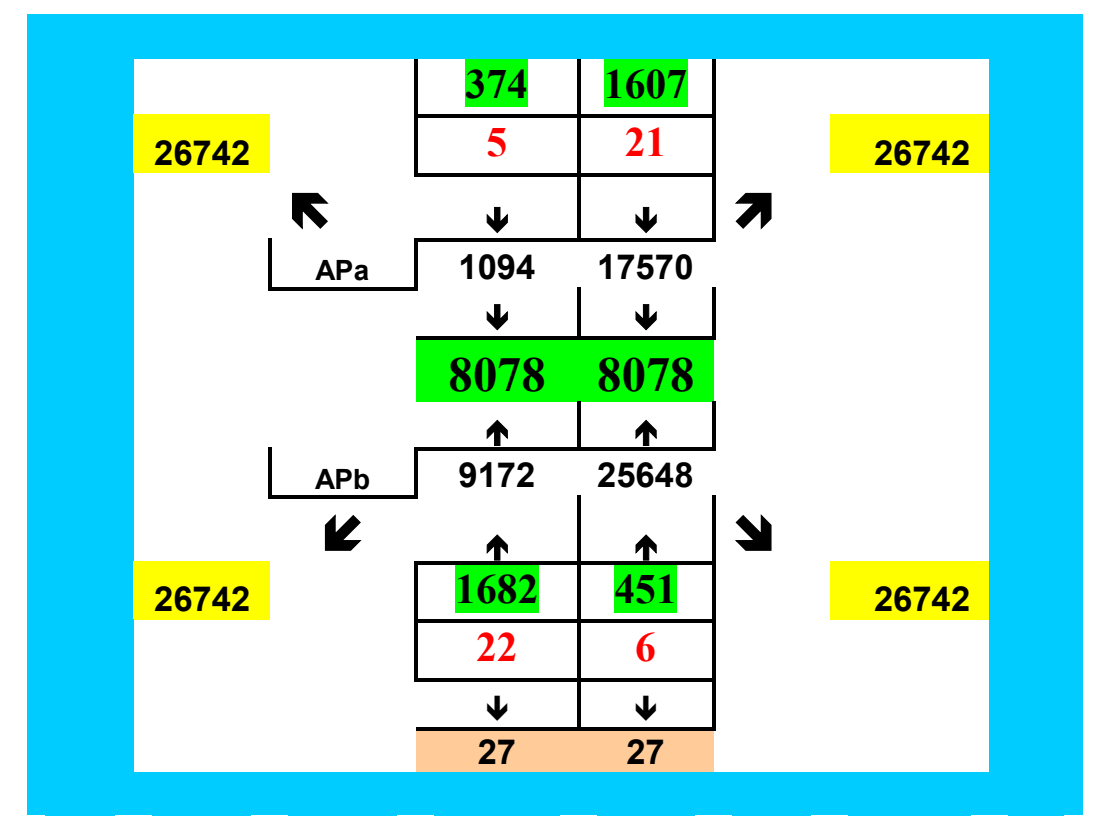

This table contains information on getting of Halley's comet in our solar system in the following years: $374,451,1607$ and 1682nd.

Arrival date of Halley's comet (6)

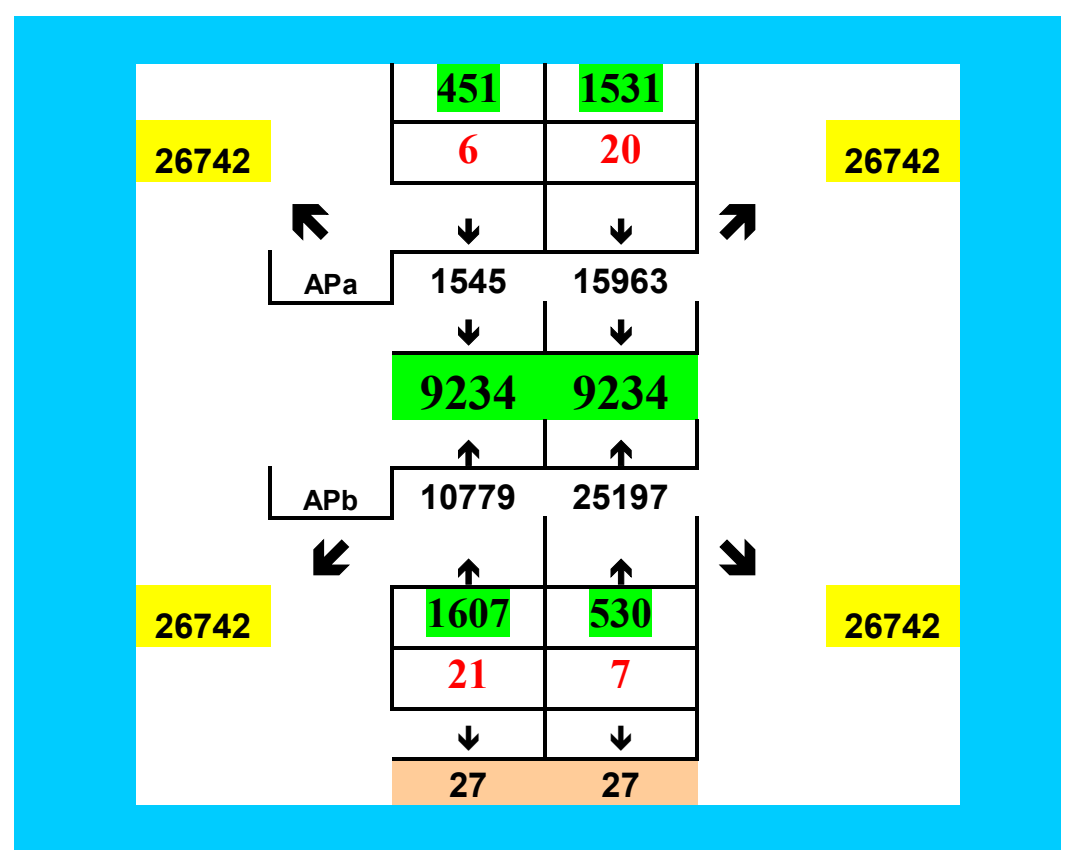


This table contains information on getting of Halley's comet in our solar system in the following years: 451, 530, 1531 and 1607nd.

Arrival date of Halley's comet (7)

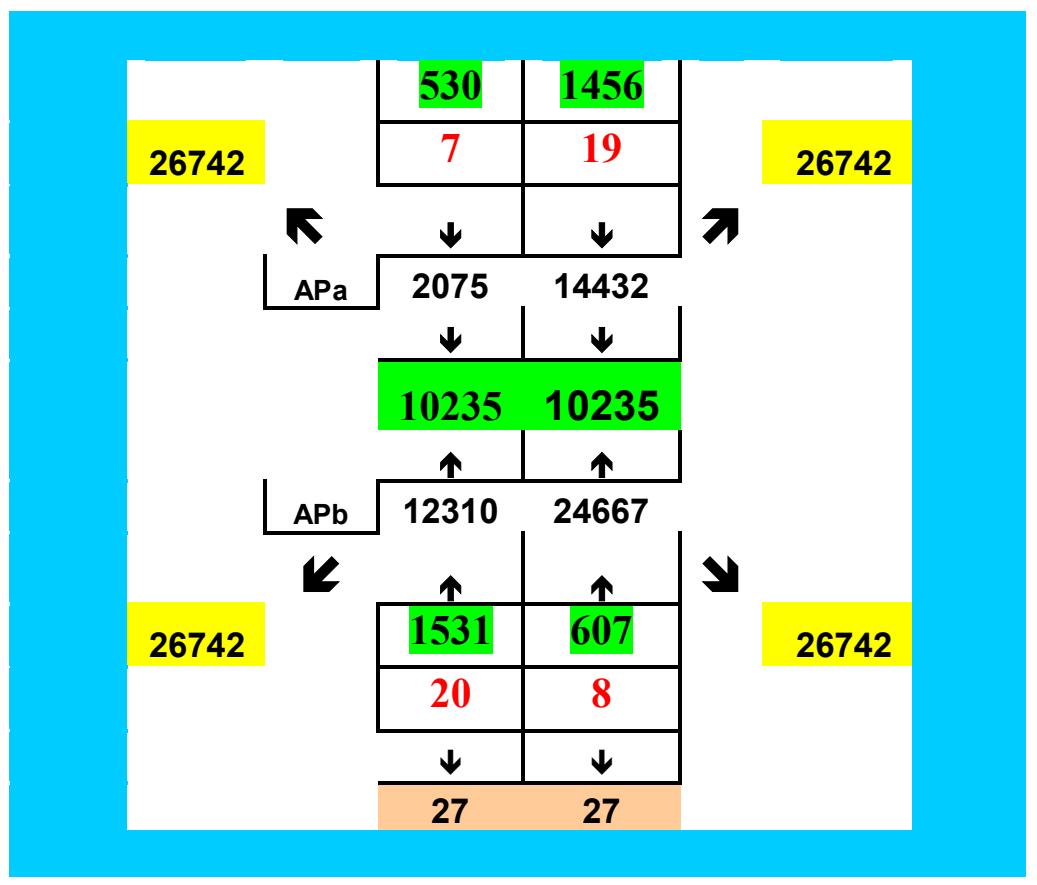

This table contains information on getting of Halley's comet in our solar system in the following years: 530, 607, 1456 and 1531nd.

Arrival date of Halley's comet (8)

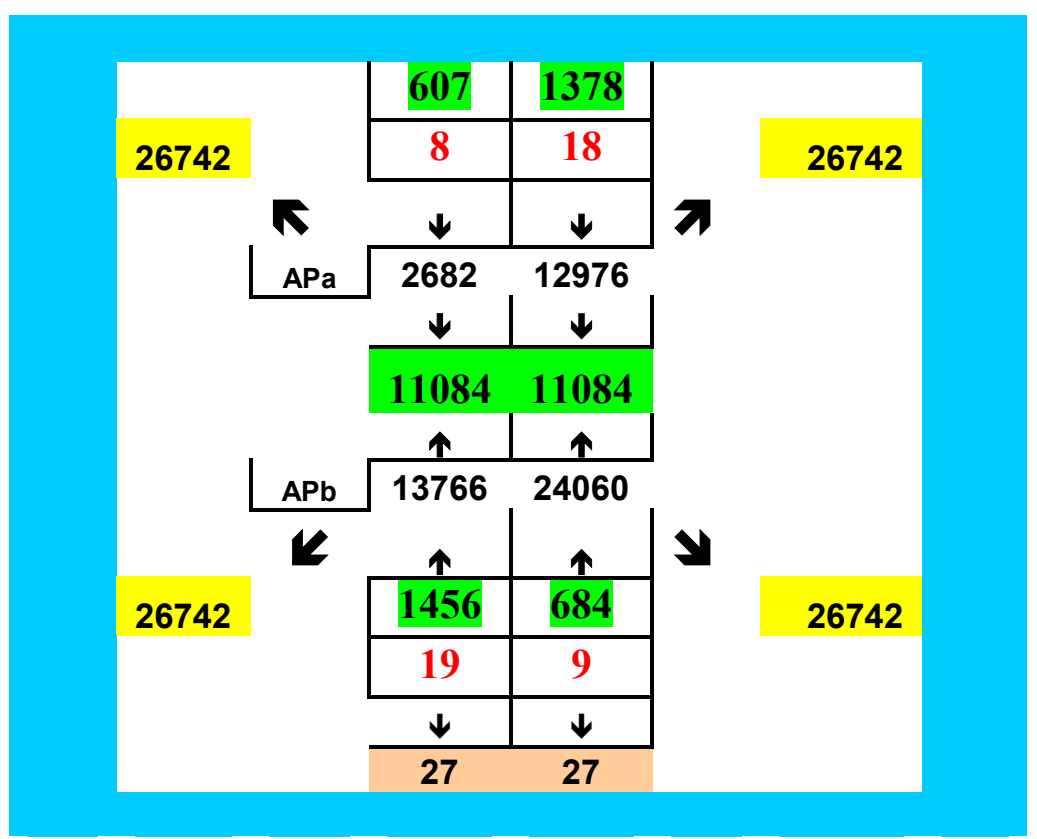


This table contains information on getting of Halley's comet in our solar system in the following years: 607, 684, 1378 and 1456nd.

Arrival date of Halley's comet (9)

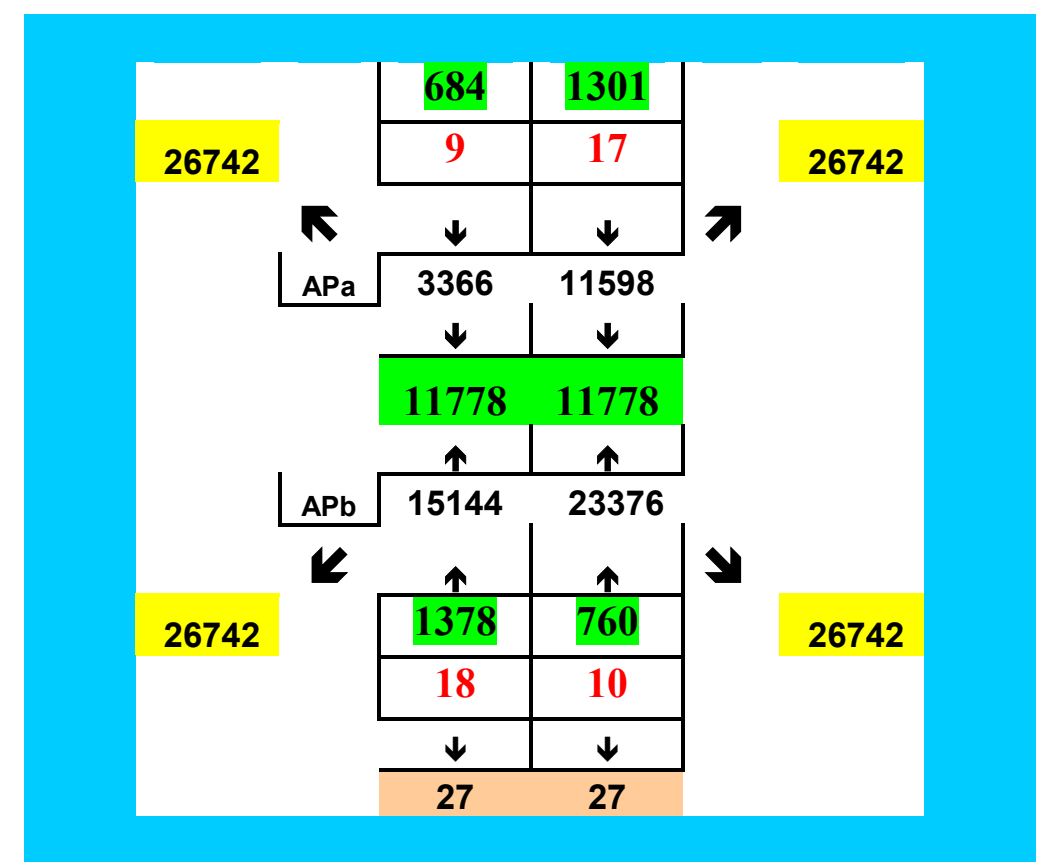

This table contains information on getting of Halley's comet in our solar system in the following years: 684, 760, 1301 and 1378nd.

Arrival date of Halley's comet (10)

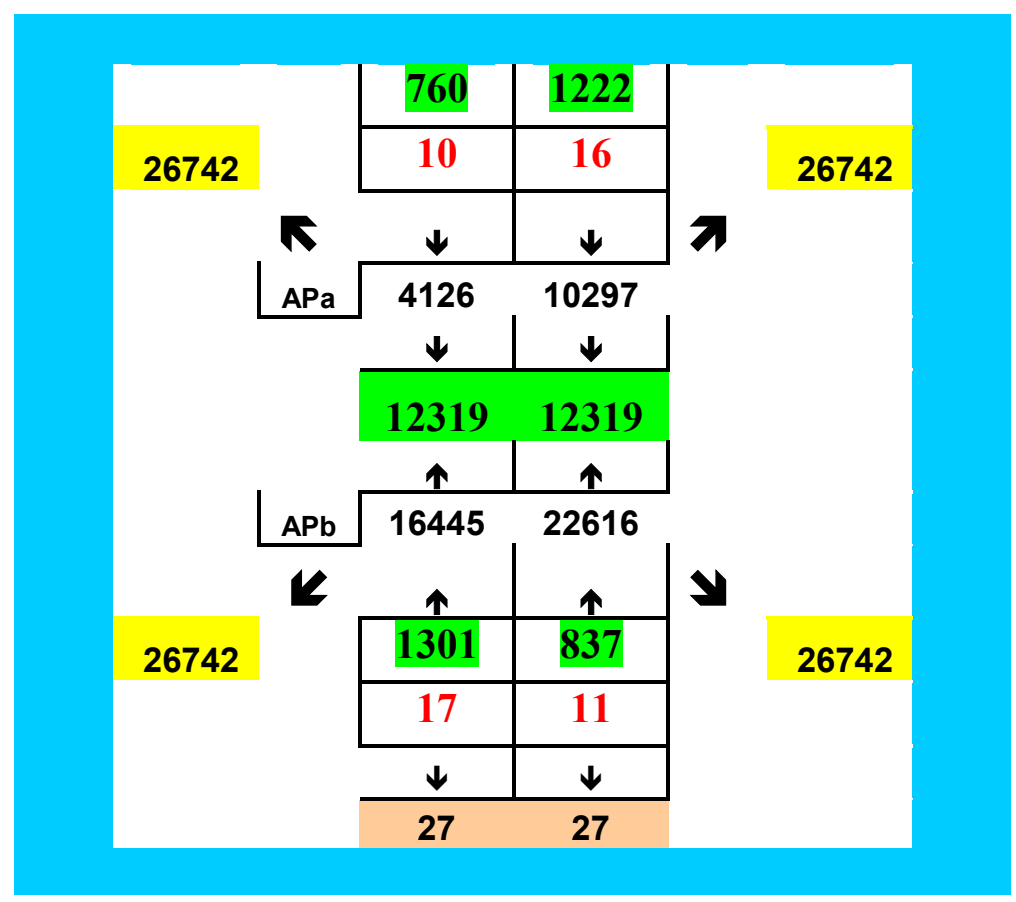


This table contains information on getting of Halley's comet in our solar system in the following years: 760, 837, 1222 and 1301nd.

Arrival date of Halley's comet (11)

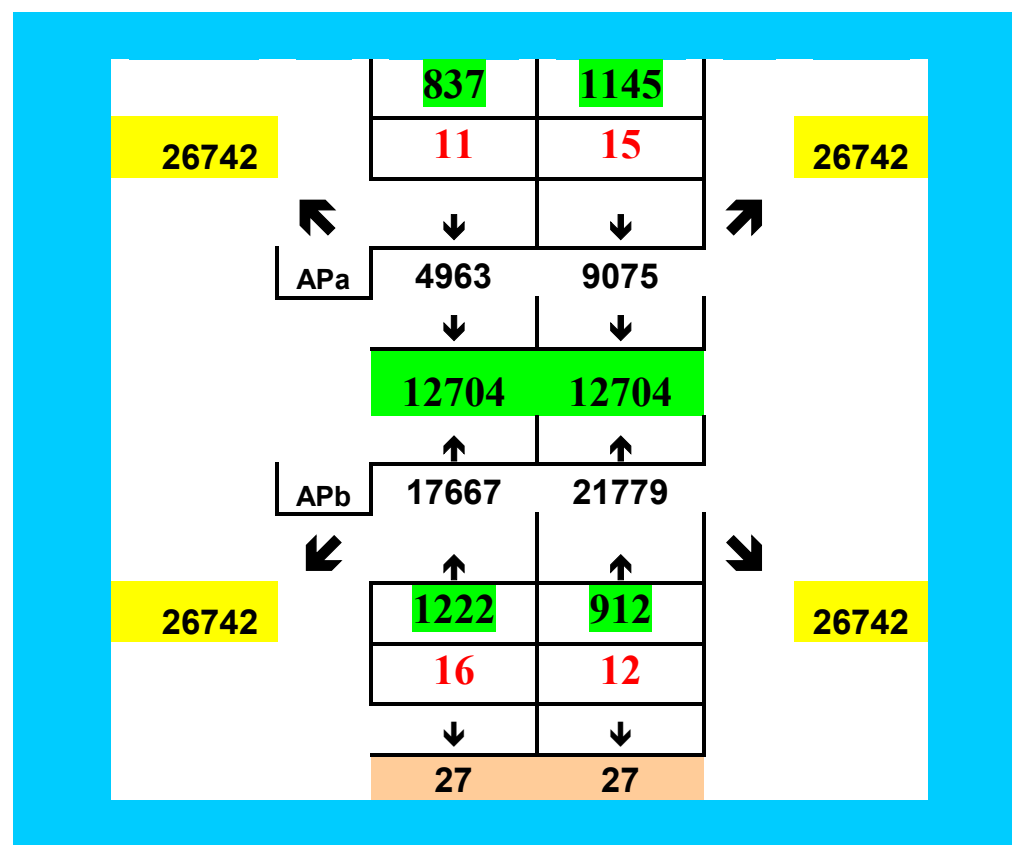

This table contains information on getting of Halley's comet in our solar system in the following years: 837, 912, 1145 and 1222nd.

Arrival date of Halley's comet (12)

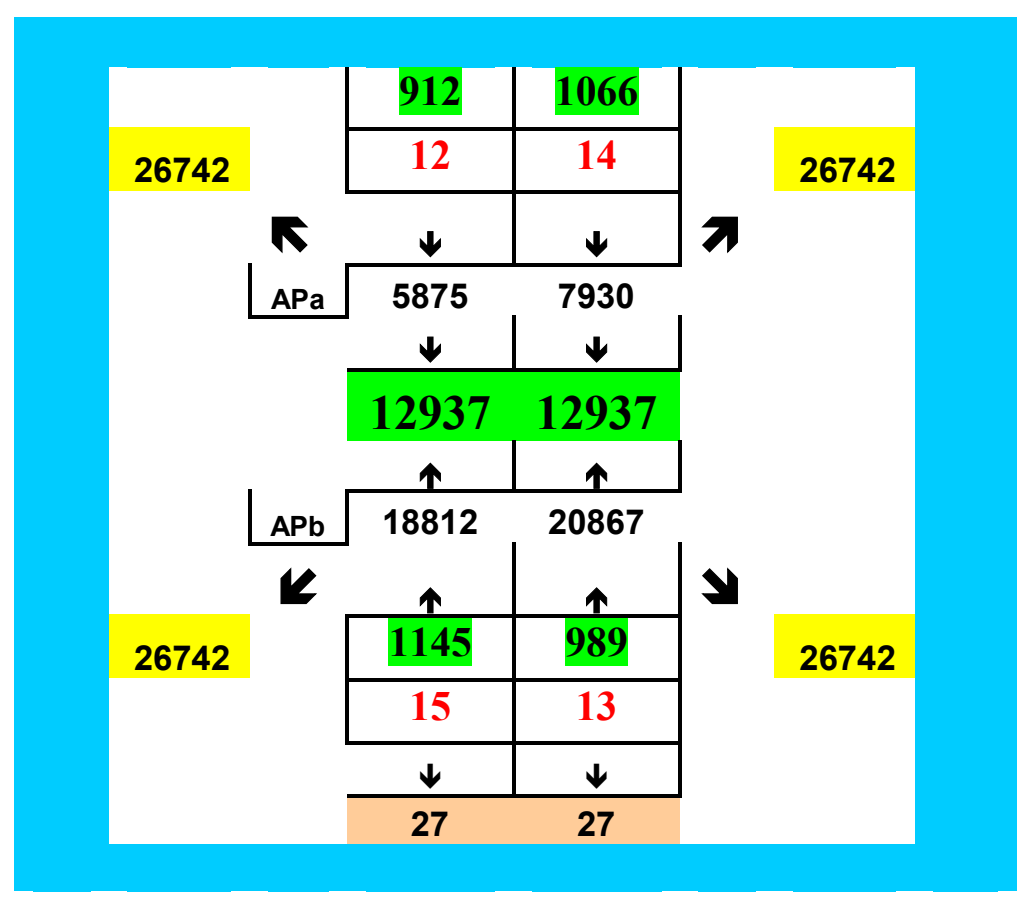


This table contains information on getting of Halley's comet in our solar system in the following years: 912, 989, 1066 and 1145nd.

Period: From 25 January 66 AD to 2137 AD

Arrival date of Halley's comet (13)

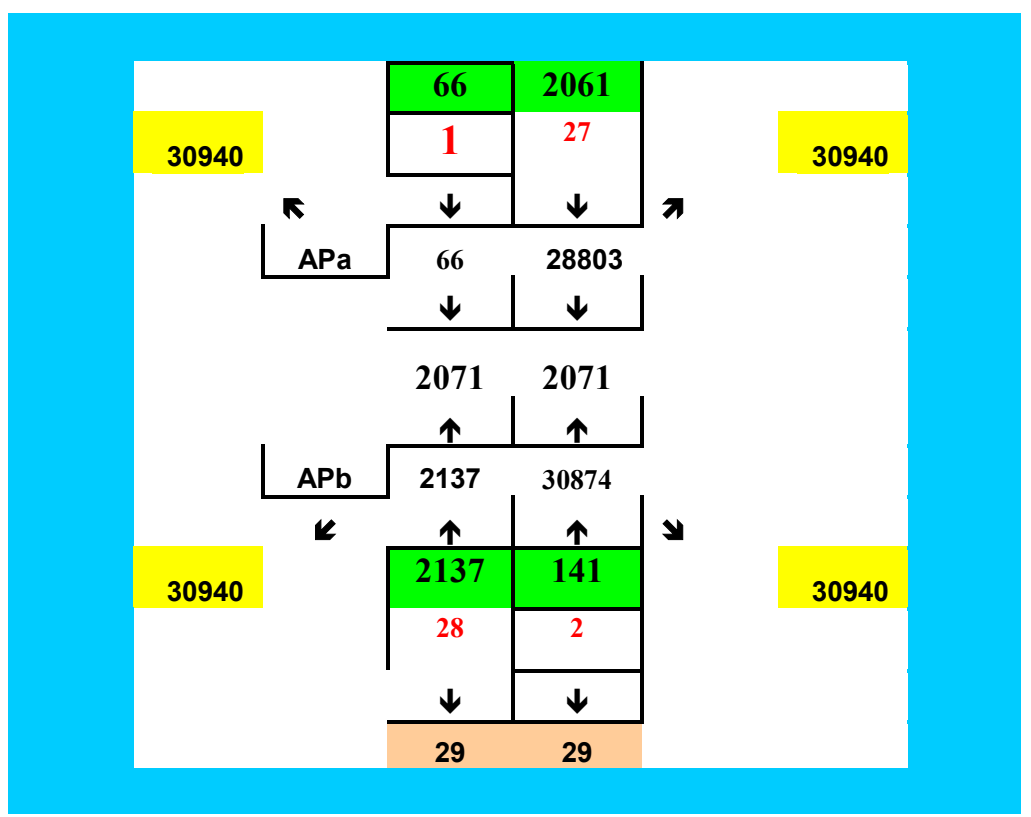

This table contains information on getting of Halley's comet in our solar system in the following years: 66, 141, 2061 and 2137nd.

Arrival date of Halley's comet (14)

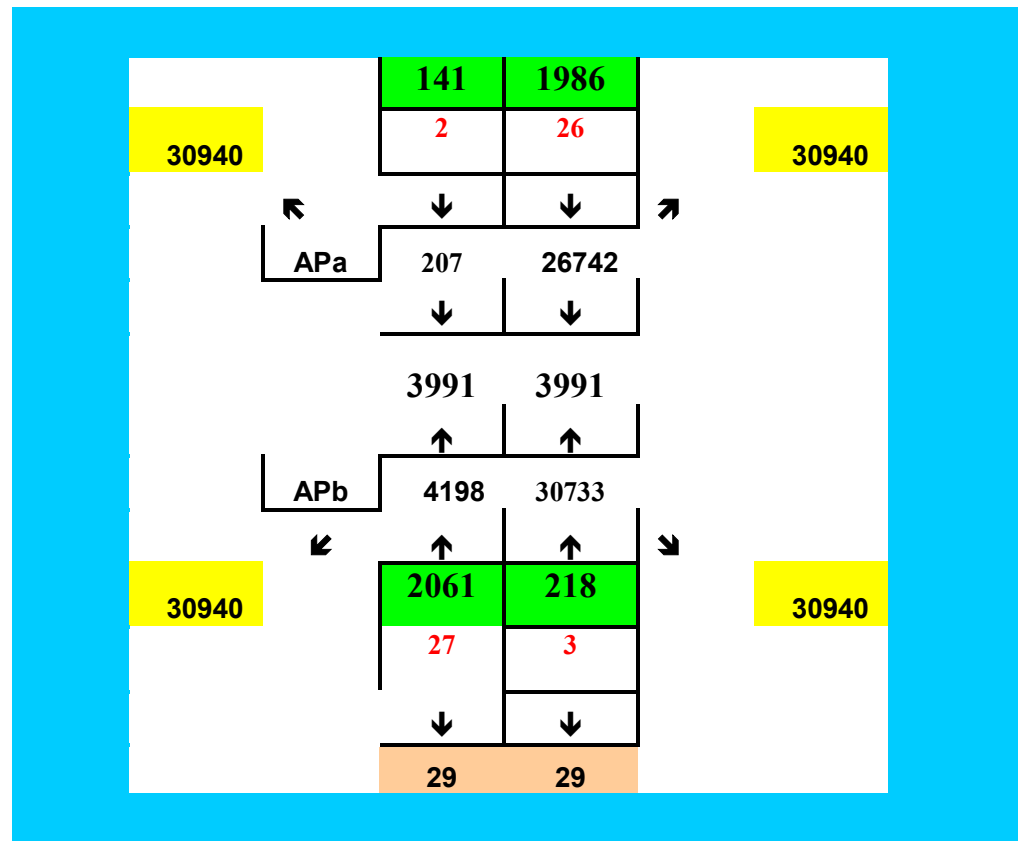


This table contains information on getting of Halley's comet in our solar system in the following years: 141, 218, 1986 and 2061nd.

\section{Arrival date of Halley's comet (15)}

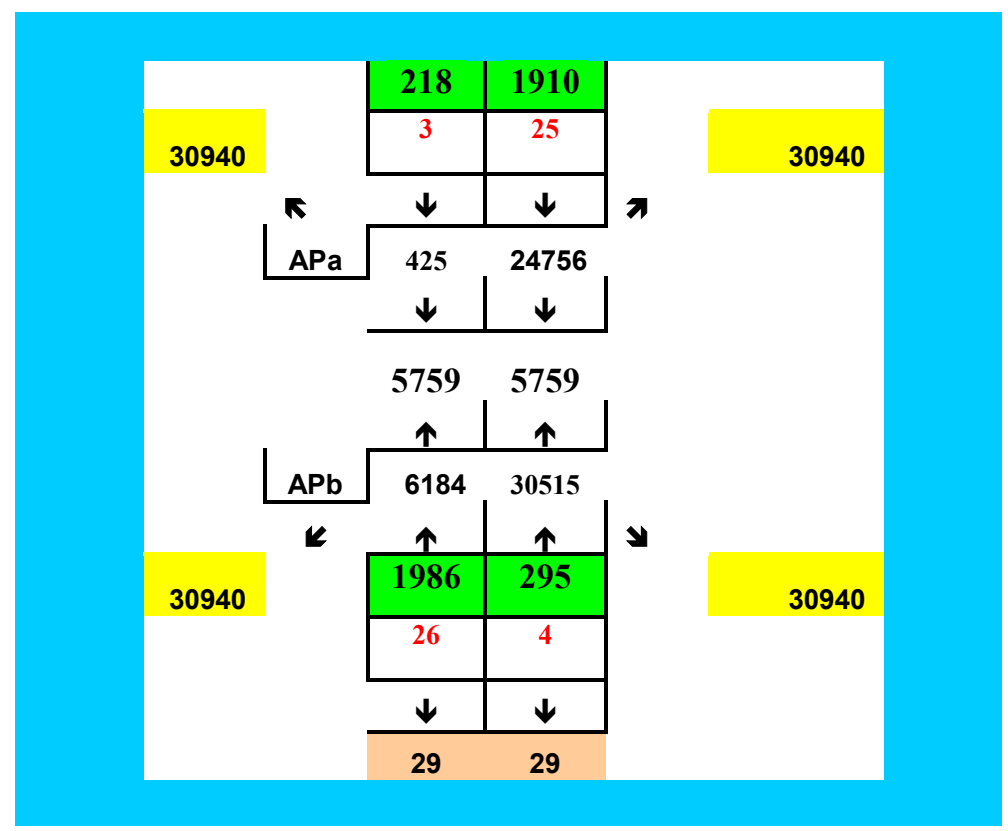

This table contains information on getting of Halley's comet in our solar system in the following years: 218, 295, 1910 and 1986nd.

etc.

\section{CONCLUSIONS}

These digital pictures reveal to us a whole new dimension to Halley's comet. They reveal to us that the cosmic process is strictly conditioned and determined by programmatic, cybernetic and information principles.

Now we have the exact scientific proofs that there is a Halley's comets language that can be described by the theory of systems and cybernetics, and which functions in accordance with certain principles.

\section{References}

[1] P. Oberc, Icarus 186(2) (2007) 303-316.

[2] Joan Johnson-Freese, Space Policy 8(3) (1992) 245-255.

[3] M. R. Combi, Icarus 81(1) (1989) 41-50.

[4] V.M. Balebanov, G.I. Zubenko, D.A. Voronov, B. Valnicek, I. Rechek, I. Rujichka, Acta Astronautica 17(8) (1988) 751-757.

[5] Y.C. Chang, Chinese Astronomy 3(1) (1979) 120-131. 
[6] Daniel Kirkwood, Journal of the Franklin Institute (93(6) (1872) 420-421.

[7] P. Oberc, Icarus 171(2) (2004) 463-486.

[8] Nicolas Thomas, Planetary and Space Science 57(10) (2009) 1106-1117.

[9] Chen Daohan, Liu Linzhong, Alan Gilmore, Advances in Space Research 21(11) (1998) 1607-1610.

[10] Susan Wyckoff, Earth-Science Reviews 30(1-2) (1991) 125-174.

[11] Zdzisław Pluta, Tadeusz Hryniewicz, International Letters of Chemistry, Physics and Astronomy 10(1) (2013) 35-47.

[12] Zdzisław Pluta, Tadeusz Hryniewicz, International Letters of Chemistry, Physics and Astronomy 8(1) (2013) 20-36

[13] Zdzisław Pluta, Tadeusz Hryniewicz, International Letters of Chemistry, Physics and Astronomy 4 (2012) 8-16.

[14] Zdzisław Pluta, Tadeusz Hryniewicz, International Letters of Chemistry, Physics and Astronomy 10(1) (2013) 35-47.

[15] Zdzisław Pluta, Tadeusz Hryniewicz, International Letters of Chemistry, Physics and Astronomy 3 (2012) 1-10.

[16] Michael A. Persinger, International Letters of Chemistry, Physics and Astronomy 2 (2014) 1-10.

[17] Zdzisław Pluta, Tadeusz Hryniewicz, International Letters of Chemistry, Physics and Astronomy 2 (2012) 28-34

[18] Zdzisław Pluta, Tadeusz Hryniewicz, International Letters of Chemistry, Physics and Astronomy 4 (2012) 1-7.

[19] Zdzisław Pluta, Tadeusz Hryniewicz, International Letters of Chemistry, Physics and Astronomy 10(2) (2013) 126-136.

[20] Tadeusz Hryniewicz, Krzysztof Rokosz, Ryszard Rokicki, International Letters of Chemistry, Physics and Astronomy 4 (2014) 98-108.

[21] Michael A. Persinger, International Letters of Chemistry, Physics and Astronomy 2 (2014) 11-14.

[22] Zdzisław Pluta, Tadeusz Hryniewicz, International Letters of Chemistry, Physics and Astronomy 3 (2012) 11-23.

[23] T. Borowski, International Letters of Chemistry, Physics and Astronomy 1 (2012) 1-5.

[24] T. Borowski, International Letters of Chemistry, Physics and Astronomy 11 (2013) 44-53.

[25] Michael A. Persinger, International Letters of Chemistry, Physics and Astronomy 12 (2013) 67-71. 